\title{
Rediscovering the record of humans
}

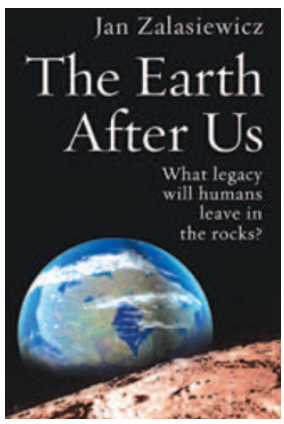

THE EARTH AFTER US

BY JAN ZALASIEWICZ

Oxford University Press: September 2008. 272 pp. £14.99
Jan Zalasiewicz is a geology teacher by profession, but apparently an epic storyteller by preference. This book takes the familiar subjects of introductory courses in Physical Geology and Earth System History and transforms them by posing a provocative premise and adding endlessly innovative touches.

The premise is that our current civilization lasts for a short while and then collapses with no survivors. Some 100 million years later, extraplanetary scientists arrive and begin to reconstruct the Earth's history. For the billions of years prior to the arrival of humans, they retrace more or less the same path taken by geoscientists during the last three centuries, although far less of the evidence remains intact after another 100 million years of continental erosion and subduction of plates. But before long, the book arrives at the question of greatest relevance to humans: if our civilization does collapse and our species becomes extinct, what will remain of our presence on Earth? From the distant perspective of 100 million years in the future, our 150,000 years or so on Earth will amount to less than the blink of an eye, and our thousands of years of civilization to just a tiny fraction of that. Erosion will have removed evidence of human habitation from higher-standing continental areas, and plate tectonics will have ensured that the remains of shipwrecks and centuries of refuse tossed overboard will have been subducted. And so - a poignant question - will anyone even know we were here?

Zalasiewicz plausibly reasons that his future space travellers will first sense a brief 'Human era' by noticing a thin interval where many odd changes seemed to happen all at once. Pollen grains that had shown a remarkable difference of plant types between continents and even regions were abruptly replaced by far more homogeneous assemblages. This shift marks the change from natural flora to cultivated crops and invasive species. Other evidence from this layer will be the near-simultaneous extinction of many of the planet's previous species. Both processes are already underway.

Eventually, sites that preserve artefacts from our brief presence will be discovered, probably in subsiding deltas into which large cities, including New Orleans, Shanghai, Venice and Amsterdam, sank slowly. The human remains likely to survive for 100 million years are not the wood, metal or concrete we use to build major structures - these will mostly fall victim to rust, rot and dissolution. Glass and some plastics may fare better in favourable subsurface environments, but our lunar artefacts - remnants of manned and unmanned missions to the Moon - will survive much better than any on Earth.

What kind of beings will these alien scientists think we were? If they find no tangible evidence of our music, poetry, prose and religious beliefs, Zalasiewicz suggests that the evidence of our brief presence will point to "a quite singular felony". Our legacy will be that of creatures who transformed most of the Earth's natural surface for agriculture, drove to extinction enough species to begin to rival the Earth's greatest natural catastrophes in order to obtain food, consumed a large portion of the Earth's natural mineral resources and vast carbon-based energy reserves to the end of enhancing their economic well-being, and caused portions of the polar ice sheets to melt and flood many coastal regions. Will the future scientists see these as the actions of a caring and enlightened species or of a self-centred and destructive one?
Scattered throughout the book is a delightful retelling of how Earth's geoscientists reconstructed its history: generations of biostratigraphers who wished for vanished species "the life of a wilder Romantic poet: early brilliant success, a worldwide reach, and then a sudden death"; and early climate scientists who sought explanations for the cause of the ice ages and "chased whole shoals of red herrings". The brilliance of this book comes from the way it escapes the grinding noise of our current political debates about human effects on climate and the environmental, stands way outside in the future and looks back in, and asks what our era was all about. In places, the imaginative prose fades for a while and lapses back toward a more straightforward telling of the history of geoscience. Most of the treatment of this science is timely, although less so for some aspects of climate science.

I highly recommend this book for geoscientists in general, and especially for those who teach introductory courses in Earth or Environmental Science and have become at least a little bored from doing so. If I'd had this book at hand when I taught Physical Geology, it would have provided endless ideas for lively ways to start and end lectures or to begin in-class discussions. I also have the sense that a shorter version of this book, shed of the non-essential Geology details and focused on the most imaginative parts, might reach a much larger public audience.

\section{William R. Ruddiman}

William R. Ruddiman is in the Department of Environmental Sciences, University of Virginia, 291 McCormick Rd, Charlottesville, Virginia, USA.

e-mail:rudds2@ntelos.net 